\title{
A small residual pressure energy power generation device
}

\author{
Junjie Tong ${ }^{1, a}$, Tianzhen Huang ${ }^{1, a}$, Biliang Zhong ${ }^{1, a}$ \\ ${ }^{1}$ Guangzhou Maritime Institute, Institute of shipping engineering, Guangzhou 510725, China \\ ajjtong9311@163.com
}

Keywords: residual pressure energy; input power; fluid fluent

\begin{abstract}
The author designed a program for utilizing residual pressure of water pipeline, by which theoretical analysis and calculation were performed and the small residual pressure energy power generation device was developed. Theoretical analysis and calculation results show that the maximum input power firstly increase and then decrease with the increase of fluid fluent. The maximum input power of small ends number was larger than more ends number.
\end{abstract}

\section{Introduction}

Resource conservation and environmental protection is China's basic national policy, promote energy conservation, accelerate the construction of resource-saving and environment-friendly society is a major strategic task of China's economic and social development [1]. The lower floors of high-rise buildings often have a large number of water supply residual pressure energy which was not used. If the residual pressure energy can be utilized efficient, the significant energy saving effect will be achieved.

Presently the residual pressure research mostly focused on high head and large flow rate fluid fluent [2-4], such as energy recovery machines and hydraulic turbine which have complex structure and the shaft sealed increasing resistance.

Therefore it is necessary to design a reliable and efficient power generation of residual pressure.

\section{Theoretical analysis of residual pressure power generation system}

\section{The program design of pipeline flow residual pressure}

The study objective is the first floor user of a 6-storied building. The duct total head is $30 \mathrm{~m}$ and the residual pressure energy power generation device is set at the duct import. The residual pressure energy generation piping system is shown as Figure 1.

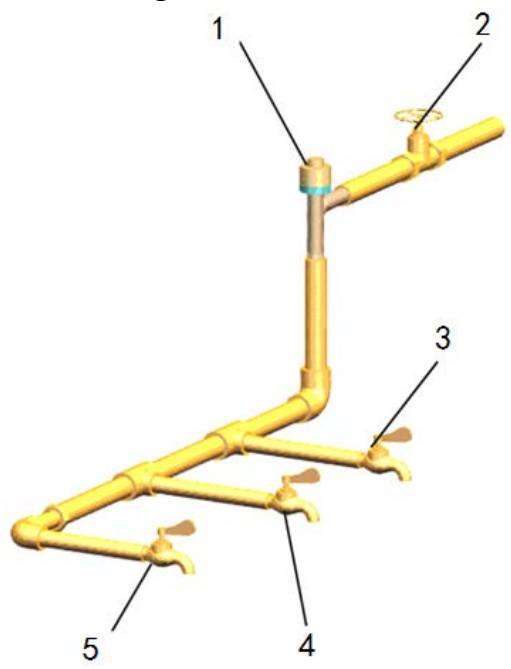

1-the generator; 2-the system valve; 3-the tub end; 4-the kitchen end; 5-the washing machine end

Fig. 1 The residual pressure energy generation piping system 
As shown in Figure 1, the residual pressure energy generation system including the generator, the system valve, the tub end, the kitchen end, the washing machine end. When either end opens, the water will drive residual pressure energy generation thereby generating electricity via battery storage reservoir.

\section{Hydraulic Calculation}

According to residual pressure energy generation piping system, theoretical design calculations were performed for water supply network users.

(1) Power generation device outlet pressure head $\mathrm{H}_{2}$ should satisfy the following formula:

$$
H_{2}=H_{a}+H_{b}+H_{c}-H_{0}
$$

Where in the above formula:

Ha represents the head of water appliance (m);

$H_{\mathrm{b}}$ represents the head of the pipeline pressure drop (m);

$H c$ represents the head of the corresponding local resistance (m);

$H_{0}$ represents the height head of generation and the water appliance (m).

(2) Pressure drop along the pipeline $\mathrm{p}_{\mathrm{f}}$ is calculated as follows [5]

$$
p_{\mathrm{f}}=\sum \lambda \frac{l u^{2}}{2 g d}
$$

Where in the above formula:

$\lambda$ represents coefficient of resistance along the pipeline.

$L$ is the pipe length (m);

$d$ is the diameter $(\mathrm{m})$;

$\mathrm{m}$ is the average tube velocity $(\mathrm{m} / \mathrm{s})$;

$g$ is the acceleration of gravity, $g=9.81 \mathrm{~m} / \mathrm{s}$

(3) The local resistance loss $P_{\mathrm{j}}$ can be calculated as [5]:

$$
p_{\mathrm{j}}=\sum \zeta \frac{u^{2}}{2 g}
$$

Where in the above formula:

$\zeta$ is pipe local resistance coefficient;

$u$ is average velocity $(\mathrm{m} / \mathrm{s})$;

(3) The input power of generation system can be calculated as:

$P_{\mathrm{i}}=\gamma Q\left(H_{1}-H_{2}\right)$

Where in the above formula:

$\gamma$ is the water specific gravity $(\mathrm{KN} / \mathrm{m} 3)$;

$\mathrm{Q}$ is the manifold flow $\left(\mathrm{m}^{3} / \mathrm{s}\right)$;

$\mathrm{H}_{1}$ is the inlet static pressure head (m);

$\mathrm{H}_{2}$ is the outlet static pressure head (m);

The relationship between the maximum input power and discharge of generation device

According to different end number, the relationship between the maximum input power and discharge of generation device are studied.

In order to save computing time, when the user terminal number is 1 , only the tub end is considered; when the user terminal number is 2, only the tub end and kitchen end are considered simultaneously; when the user terminal number is 3 , the tub end, kitchen water end and washing machine end are considered simultaneously.

When the user terminal number is 1,2 and 3 respectively, the maximum input power of the power generating varies with fluent fluid is shown as fig 2, fig 3 and fig 4 respectively.

As shown in Fig. 2 to Fig.4, the maximum input power firstly increase and then decrease with the increase of fluid fluent. The maximum input power of small ends number was larger than more ends number.

It is analyzed that pipeline resistance loss grew when more ends were open he open end of the large due to growth of fluent fluid, the maximum input power reduced. 


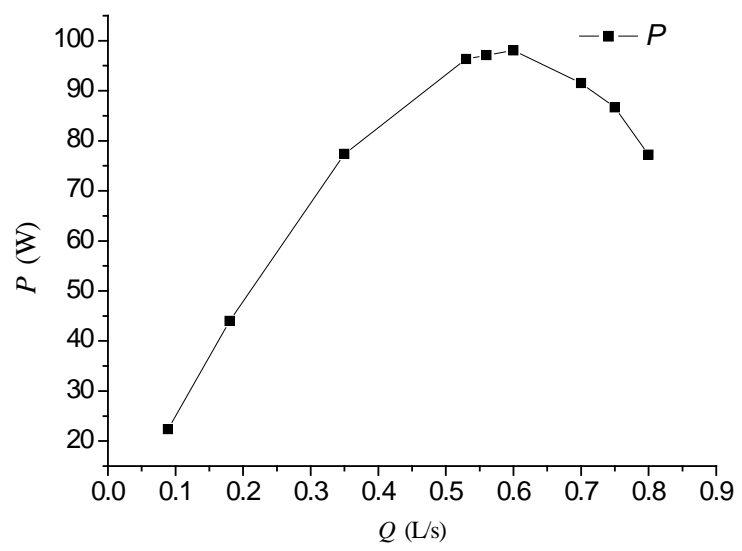

Fig.2 The Maximum input power varies with fluent fluid when the user terminal number is 1

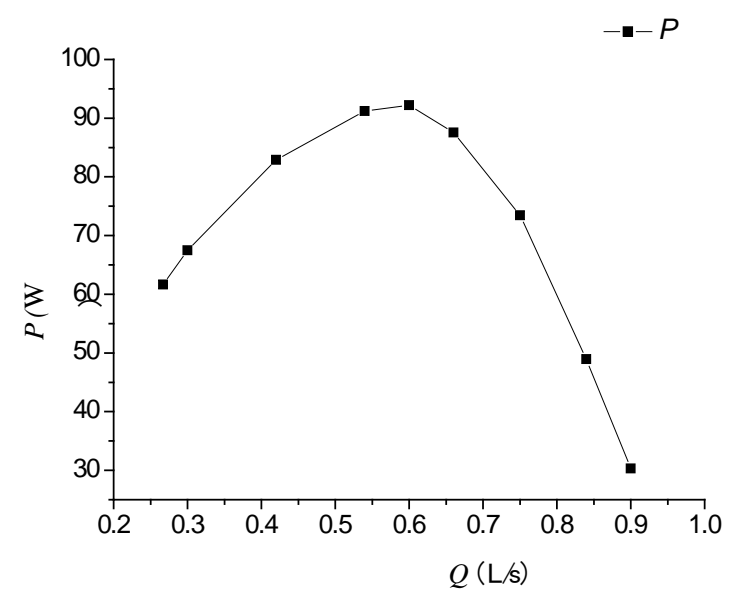

Fig.3 The Maximum input power varies with fluent fluid when the user terminal number is 2

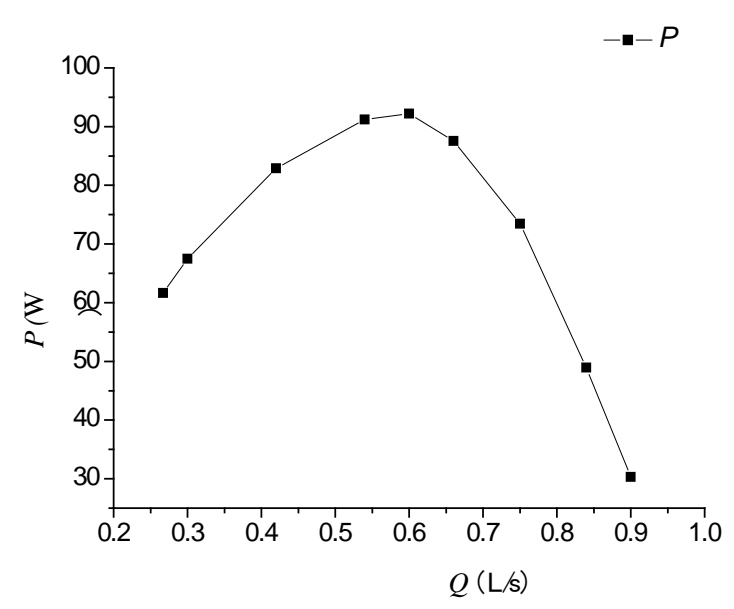

Fig.4 The Maximum input power varies with fluent fluid with fluent fluid when the user terminal number is 3

\section{The design of generation device}

According to the pipe system, the generation device structure was designed. The sectional view of a residual pressure energy generation design is shown as Fig 5, The physical structure of generation was shown in Figure 6. The Residual pressure energy generation test system in Fig 7, The Residual pressure energy generation driving the LED and fan is shown in Fig 8 and Fig 9 respectively. 


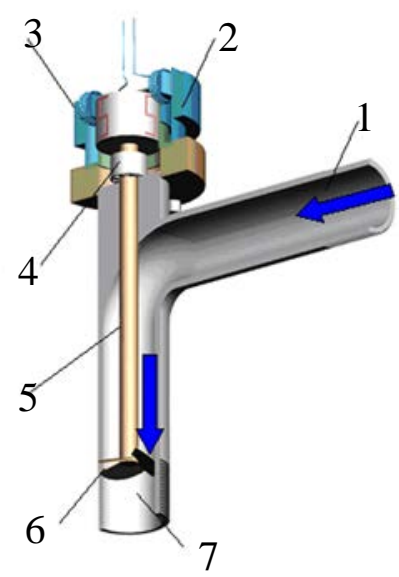

1-inlet; 2-stator; 3-rotor; 4-bearing; 5-shaft; 6-impeller;7-outlet Fig. 5 The sectional view of a residual pressure energy generation design

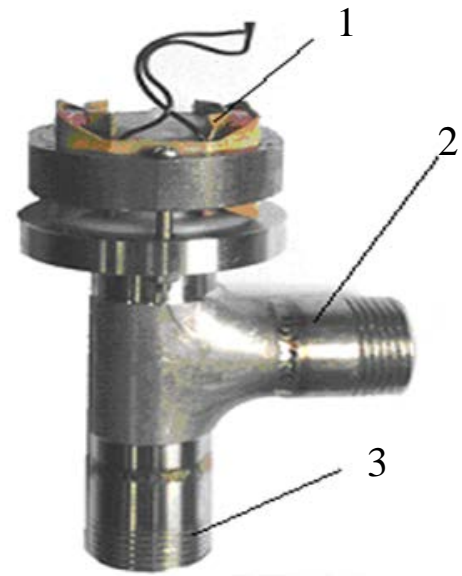

1-stator; 2-inlet;3-outlet

Fig.6 The physical structure of generation

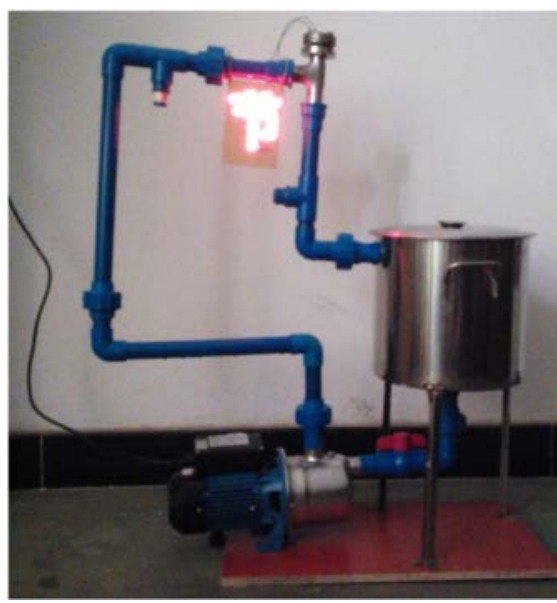

Fig 8

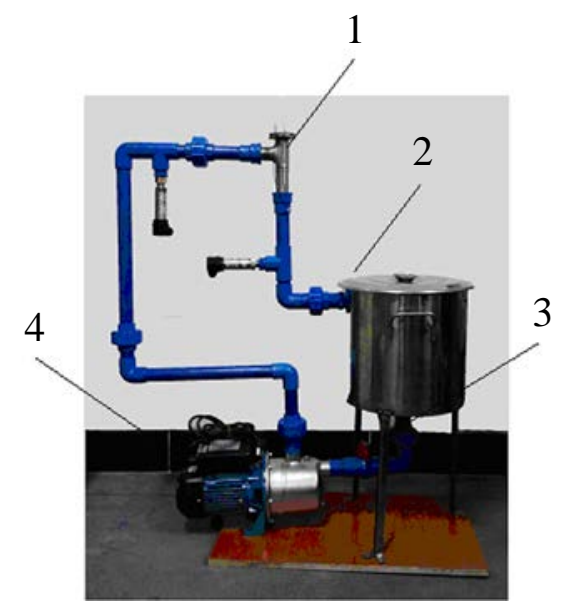

1-generator; 2-storage tank;3-valve;4-pumb

Fig.7 The Residual pressure energy generation test system

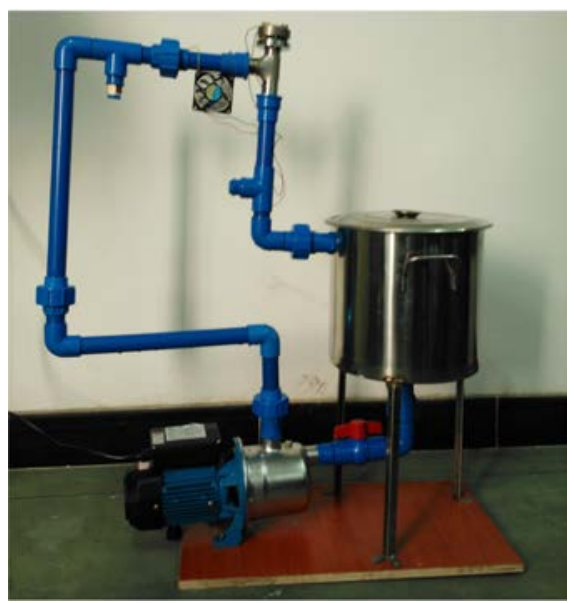

Fig 9

As was seen from Fig 5 and Fig 6, the water flows from the inlet, pushing power generation device through axial rotation of the impeller, the generator rotating, stator core and the induction coil current is obtained.

As it can be seen from Fig 8 and Fig 9, the small residual pressure power generation device can successfully drive LED light emitting unit and fan, At the same time, the average voltage of 34.5V test, the average power of $12.6 \mathrm{~W}$. 


\section{Conclusions}

(1) the maximum input power firstly increase and then decrease with the increase of fluid fluent. The maximum input power of small ends number was larger than more ends number.

(2) the small residual pressure power generation device can successfully drive LED light emitting unit and fan, At the same time, the average voltage of $34.5 \mathrm{~V}$ test, the average power of $12.6 \mathrm{~W}$.

\section{Acknowledgements}

This work was financially supported by the Natural Science Foundation of Guangdong Province, China (NO2015A030313819), the Science and Technology Project of Guangzhou City Huangpu District, China (NO201543) and Guangdong Provincial Transportation Department project (NO201502047)

\section{References}

[1] The Central People's Government of People's Republic of China. Energy saving "Twelfth Five-Year Plan" [S]. 2012.08.06. (in Chinese)

[2] Sun Yeshan,You Yage et al, 10t/d pilot study efficient reverse osmosis desalination plant energy [J] Salt and Chemical 2007.36 (2): 13-16(in Chinese)

[3] A lex Gruendisch. Re-Engineering of Pelton Turbine for seawater \& Brackish Water Energy Recovery[J], Desalination \& Water reuse, 1999(3):16-23

[4] Rchard L. Stover. Development of a fourth generation energy recovery device. Desalination, 2004(165):313-321

[5] Long Tianyu, Cai Zengji, The fluid mechanics pump and fan [M]. Beijing: China Building Industry Press, 2011(in chinese) 